\title{
Life Cycle Assessment for Evaluating On-farm Energy Production: The Case of Sunflower Oil
}

\author{
Lara Riello, Stefano Bona* \\ Dipartimento di Agronomia Ambientale e Produzioni Vegetali, Università di Padova \\ Agripolis - Viale dell'Università 16, 35020 Legnaro (Pd), Italy
}

\begin{abstract}
The main objective of this work was to evaluate the production of sunflower oil as a source of bioenergy and its use on the farm. Representative farms of the Veneto Region were analyzed in order to evaluate the possibility of using different biofuels. The results showed that there are only a few feasible alternatives at farm level. The conversion of oil to biodiesel appeared unachievable because of the large number of hectares necessary for optimizing use of the transesterification equipment. A life cycle environmental analysis (LCA) was applied to eight different farm types simulating the total replacement of diesel oil by pure vegetable oil (sunflower). The results were not uniform because, considering all the LCA impact categories, some of them turned to be worse than the original scenario (use of diesel oil) but there was a substantial advantage for all the farm types in terms of reduction of substances with effects on climate change. Some farms, termed horticultural farm large, unspecialized farm large and unspecialized farm small, had a reduction of more than $99 \%$ in the substances with effects on climate change by changing from diesel oil to sunflower oil. The biofuel is not yet competitive as no free market exists for it, but it represents a practical way to avoid the shift of economic benefits from agriculture to industry, as happens with biodiesel production.
\end{abstract}

Key-words: sunflower, oil, energy, biofuel, LCA.

\section{Introduction}

Biomass is one of the main renewable energy resources for the future. It offers an enormous flexibility of supply and is widely available in the form of crop residues disposal or specific cultivations, etc. It can be burned directly (thermo-chemical processes) or converted by chemical and biochemical processes into liquid, solid or gaseous biofuels. The end-product of the extraction process is crude oil, in the form of oil cake or expeller if the extraction is mechanical, flour if the extraction is chemical.

Vegetable oils are interesting alternatives to fossil fuel owing to their relatively low production costs. They are easy to produce and therefore utilisable in situations (underdeveloped nations, farms in marginal areas or with high energy consumption) where home-produced energy at low cost is a requirement (Riello and Bona, 2005; Scrosta, 2005; Bernardo et al., 2003; Al-Hasan, 2002).
In Italy, the use of sunflower oil is particularly worth studying as the crop is well adapted to the conditions in the country and requires low inputs.

The chemical/physical properties of sunflower oil affect its performance if used as fuel in endothermic engines (Schlick et al., 1988). In table 1 the main chemical-physical characteristics of sunflower oil are compared with diesel oil. One of the most interesting is the viscosity; at $38{ }^{\circ} \mathrm{C}$, sunflower oil has a viscosity approximately 14 times higher than diesel oil. The elevated viscosity influences the injection system and induces an insufficient atomization of fuel in the combustion chamber, provoking a "dirty" combustion which negatively affects the engine lifespan (Kaufman et al., 1986). As the viscosity decreases with increasing temperature it can be reduced by heating oils or filters, tanks or culverts prior to the injectors. The latest generation diesel engines (common-rail), which have a high fuel pressure before the injection systems 
Table 1. Main properties of sunflower oil and diesel, plus sunflower oil/diesel (SO/D) ratio. (Source: CTI, 1993)

\begin{tabular}{|c|c|c|c|}
\hline Properties & Sunflower oil & Diesel & $\mathrm{SO} / \mathrm{D}$ \\
\hline Density $20^{\circ} \mathrm{C}\left(\mathrm{kg} \mathrm{dm}^{-3}\right)$ & 0.915 & 0.82 & 1.115 \\
\hline (cSt) Viscosity at $38^{\circ} \mathrm{C}$ & 37.1 & 2.7 & 13.740 \\
\hline (LHV) Lower heating value $\left(\mathrm{MJ} \mathrm{dm}^{-3}\right)$ & 32.9 & 35.8 & 0.919 \\
\hline (CN) Cetane Number & 37 & 47 & 0.787 \\
\hline (FP) Flash Point $\left({ }^{\circ} \mathrm{C}\right)$ & 274 & 68 & 4.029 \\
\hline (SP) Solidification Point $\left({ }^{\circ} \mathrm{C}\right)$ & -18 & $*$ & * \\
\hline (IN) Iodine number & $110-143$ & $* *$ & $* *$ \\
\hline
\end{tabular}

(*) Depending on the type of diesel; (**) Analysis not applicable.

can markedly reduce this disadvantage (Scrosta, 2005).

The lower heating value (LHV) of sunflower oil is below that of diesel oil, which means higher specific consumption to obtain the same power (around 5-8\%, Scrosta, 2005).

The cetane number $(\mathrm{CN})$ indicates the behaviour of fuel in the ignition chamber. The number is proportional to the necessary pressure for self-ignition of the air-fuel mixture. It influences cold starts, combustion, maximum pressure and engine noise. The optimal range is around 40-50, so sunflower oil (with 37) is not far below this value, even if it is worse than diesel oil.

The flash point (FP) is the minimum temperature at which the fuel vapour ignites in the presence of a flame. Sunflower oil has a much higher flash point than diesel. It is therefore easy to store, handle and transport. A low value can be a symptom of the presence of extraneous inflammable substances, for example methanol in biodiesel.

The solidification point (SP) represents the temperature at which an oil solidifies, making it necessary to preheat the oil before transferring it from tanks to injection pumps.

The iodine number (IN) gives information on the degree of insaturation of the oil. The higher the index is, the higher is the insaturation degree. Overly high values compromise the stability (the double bonds are unstable and fatty acids often polymerize), causing rubber formation and deposition; this is highly undesirable in engines. Instead, too low values (indicating a high saturated fatty acid content) influence the behaviour at low temperatures (oil is too viscous). For storing pure vegetable oil for long periods without problems of loss of the physi$\mathrm{cal} /$ chemical characteristics, an iodine number lower than 25 is recommended. Sunflower oil has a high iodine number and therefore its longterm storage, with consequent rancidification of the oil, can cause rapid engine deterioration; in particular, by reducing the life of injector pumps and injectors. Sunflower varieties with high oleic acid content are available on the market: this oil has lower IN values with a consequent increase in oxidative stability (McDonnell et al., 2000). This involves an increase in the oil viscosity (Araya et al., 1987; Scrosta, 2005) but this disadvantage can easily be overcome by heating the oil.

Oil can be extracted in many different ways but, on farms, the simplest is cold pressing. Sunflower oil extracted by press systems has suitable chemical/physical characteristics for use as biofuels in endothermic engines.

The use of vegetable oils has already been widely tested and adopted in many parts of the world (Kaufman et al., 1986). In Europe, Germany has the highest rate of substitution of diesel by oil (Francescato and Boschetti, 2005). In Austria a large number of small mills cooperate in the production of vegetable oil for energy purposes (Francescato and Boschetti, 2005). It should be taken into account that companies are widely available in the German speaking area that can convert tractors to the use of vegetable oil, so this obviously increases the number of farmers interested in using oil as a source of energy.

\section{Life Cycle Assessment (LCA)}

Life Cycle Assessment (LCA), which has evolved from energy analysis, was first applied at the end of the 1960s, when some industries began to take an interest in conserving resources and controlling polluting emissions into 
the atmosphere. A global vision of the production system, without any separate analysis of individual production processes, is typical of LCA. Moreover, LCA uses neither economic nor social variables but just flows of matter and energy. Recent European policy and the introduction of standards "ISO series 14000" (UNI EN ISO 14040, 1998; UNI EN ISO 14041, 1999; UNI EN ISO 14043, 2001) have increased the use of procedures for controlling production efficiency in terms of energy and the environment. The fundamental approach of this from cradle to grave methodology is a systematic analysis of the flows of matter and energy during the life of a product - from the extraction of the raw materials, through production, its use, until the product is disposed of and becomes refuse. There are two main reasons for using this approach:

1) first of all, a single operation can apparently be considered more efficient and "cleaner" simply by transferring the pollution elsewhere without any real improvement (Pivato and Tamiozzo, 2003);

2) engineers traditionally concentrated their efforts on increasing the efficiency of a single production process without considering the entire production chain (Pivato and Tamiozzo, 2003).

The phases of the methodology are complex and their definition is beyond the scope of this paper, but it is worth emphasizing that the procedure outputs are "impacts on different environmental categories" indicating the entity of environmental modifications generated by production activities. Flows of matter and energy affect different categories of impact (UNI EN ISO 14043): global warming, stratospheric ozone depletion, acidification, nutrient enrichment, photosmog formation, human and eco-toxicity and resources depletion.

The classification phase of LCA is probably the most important; it consists of organizing the inventory data, which are the values of all the gas, liquid and solid emissions caused directly and indirectly by the considered operations, and associating them to the categories of impact. The limits of LCA regard the subjectivity of the choice of data and the location of the borders of the system analyzed.

Life Cycle Assessment has another important limitation: it does not consider the time/space scale; in LCA space and time simply do not exist! This can limit the analysis because pollution is usually considered relevant if it is concentrated in time and space.

The scope of this work was to evaluate the use of sunflower oil on the farms to meet their internal energy requirements. LCA was used to analyze the effective possibility of using this biofuel and to estimate the consequent changes in farm organization. The case study consisted of a group of typical northern-Italian farms in the Po Valley.

\section{Materials and methods}

With the aim of evaluating the applicability of a conversion from diesel oil to sunflower oil on farms, the first step was to collect data on the economic/technical organization of farms in the Po Valley.

We chose different sources of data.

The data available from the last census on agriculture proved to be too aggregated and out of date to be used in the simulation. The data from RICA (2004) resulted as being unrepresentative of the Po Valley situation. Given that supplying information to RICA is on a voluntary basis, the sample is mainly composed of medium/small farms. It is also little representative of cattle farms: as the main by-product of sunflower oil extraction is oil cake, which is mainly used as cattle feed, these data could not be used either. We therefore chose to perform the simulation using data from our own survey in the Veneto area. Farms were chosen on the basis of the RICA survey typologies and the data came from questionnaires on the distribution of crops, farm cropping techniques and the presence/absence of livestock and greenhouses/tunnels. Thirty farmers were interviewed; the group was tested for fitting the OTE criteria (economic technical average) typical of a RICA questionnaire. Eight were then chosen, because of the completeness of their data, to take part in the sample considered for the simulation and these were grouped by OTE and dimensions (Table 2). It should be noted that small farm is the norm for the Veneto Region, with less than $5 \%$ being termed large farm.

Using LCA analysis we estimated the impact of different types and sizes of farms under two types of management: 
Table 2. Available land (ha) of the farms considered for the simulation.

\begin{tabular}{lcc}
\hline Farm Type & Small & Large \\
\hline Unspecialized farm & 1.72 & 84.0 \\
Horticultural farm & 1.20 & 22.5 \\
Cattle farm & 1.70 & 53.0 \\
Mixed farm & 1.56 & 35.0 \\
\hline
\end{tabular}

1) traditional management: energy source = diesel;

2) renewable management: energy source = sunflower oil.

\subsection{Farm organization}

As it was decided to simulate the production of energy on the farm, crop distribution was rearranged in order to assign land to growing sunflower for the necessary oil supply. The crops (Tassinari, 1996) were transformed into energy data using the parameters defined by Riello and Bona (2005). The sunflower surface area was defined on the basis of the energy requirements of the farm, whereas the surface area of other crops reflects, where possible, the percentage distribution before the introduction of sunflower. In the case of presence of cattle, oil cake was assumed to replace forage maize, so the cropping areas were reorganised in order to provide a balanced amount of oil cake and forage maize ${ }^{1}$. We simulated feeding bullocks with the oil cake because these animals present few problems of digestion with this new feed in their diet.

The sizes of warehouses and tanks for the oil produced have also been taken into account in the simulations. Obviously, having harvested the sunflower, space must be found in a warehouse for all the seeds, but once the oil cakes are produced these can be stored in the same warehouse. The tanks for oil storage were dimensioned following the patterns of consumption and taking into account that a minimum storage must be guaranteed (we assumed a quota of $1 / 6$ of the total annual production in order to have an oil reserve for about 2 months in case of machinery breakdown). Lastly, we took into account that the produced oil, being unrefined, rapidly becomes rancid (Mosca,

\footnotetext{
${ }^{1}$ In the simulation, seed pressing has been assumed to
} extract about $85 \%$ of oil.
1998) and so the production rhythm must follow the rate of consumption.

Since only larger farms would have the space and organization for pressing/filtration systems (with silos, tanks etc.), for the simulations, we chose to attribute only a quota of use of the systems. The same quota was assumed for these machines occupying land.

We lastly hypothesized that all the farm tractors were converted for the use of sunflower oil as fuel.

\subsection{Calculation of the hectares of sunflower for energy self-production on the farm}

Farms must assign part of the land to sunflower in order to use its oil as a source of energy for: soil tillage, crop protection, heating the farmhouse and greenhouses (if present), etc.

The mathematical formulation of this is the solution of a system with bonds.

Before passing to the definition of equations, all the variables can be found listed in table 3 .

The problem is to find the HaS amount to satisfy the total consumption Ctot under bonds: 1) total hectares must remain constant

$$
\sum_{j} H a F_{j}+H a S=\sum_{j} H a T o t=C O N S T A N T
$$

2) the percentage of hectares (sunflower excluded) growing the $\mathrm{j}^{\text {th }}$ crop must remain fixed

Table 3. Variables used for estimating crop redistribution following the use of sunflower oil as energy source.

\begin{tabular}{|c|c|}
\hline Name & Description \\
\hline HaTot & Total farm hectares \\
\hline $\mathrm{HaI}_{\mathrm{j}}$ & Hectares available for the $\mathrm{j}^{\text {th }}$ crop (Initial) \\
\hline $\mathrm{HaA}$ & $\begin{array}{l}\text { Hectares available after the introduction of } \\
\text { sunflower (HaTot-HaS) }\end{array}$ \\
\hline$\% h_{j}$ & $\begin{array}{l}\text { Percentage of hectares occupied by the } \mathrm{j}^{\text {th }} \\
\text { crop before the introduction of sunflower } \\
\text { (HaI/HaTot) }\end{array}$ \\
\hline $\mathrm{HaF}_{\mathrm{j}}$ & $\begin{array}{l}\text { Hectares for the } j^{\text {th }} \text { crop after the introduc- } \\
\text { tion of sunflower }\end{array}$ \\
\hline $\mathrm{CSp}_{\mathrm{j}}$ & Specific fuel consumption for the $\mathrm{j}^{\text {th }}$ crop \\
\hline CSpS & Specific fuel consumption for the sunflower \\
\hline Heat & Heating of house and greenhouse \\
\hline CTot & Total consumption (energy) \\
\hline SY & Sunflower yield \\
\hline$\%$ Oil & Percentage of oil in sunflower seeds \\
\hline QOil & Quantity of oil to be produced $(\mathrm{kg})$ \\
\hline $\mathrm{HaS}$ & Hectares for sunflower \\
\hline $\mathrm{j}$ & Crop Index \\
\hline
\end{tabular}


3) the HaS amount must always be $>=0$.

$$
\begin{aligned}
& H a F_{j}=\% h_{j} * H a A \\
& \% h_{j}=\frac{H a F_{j}}{H a A}=\mathrm{constant}
\end{aligned}
$$

So the system becomes:

$$
\left\{\begin{array}{l}
\sum_{j} \mathrm{HaF}_{j} * \mathrm{CSp}_{j}+\mathrm{HaS} * \mathrm{CSpS}+\mathrm{Heat}=\mathrm{CTot} \\
\mathrm{CTot}=\mathrm{QOil}=\mathrm{HaS} * \mathrm{SY} * \% \mathrm{Oil} \\
\mathrm{HaF}_{j}=\% \mathrm{~h}_{j} * \mathrm{HaA} \\
\mathrm{HaS} \geq 0
\end{array}\right.
$$

The unknown variables of the system are $\mathrm{HaS}$, QOil and $\mathrm{HaF}_{\mathrm{j}}$ : $(\mathrm{j}+2)$ equations in $(\mathrm{j}+2)$ unknown variables (the system admits solution).

Solving the system it is possible to obtain the value of $\mathrm{HaS}$ as:

$$
H a S=\frac{\text { Heat }+H a T o t * \sum_{j} \% h_{j} * C S p_{j}}{\sum_{j} \% h_{j} * C S p_{j}+S Y * \% O i l-C S p S}
$$

The other unknown variables are all deducible from this value, using the equations

and therefore the final $\mathrm{j}^{\text {th }}$ crop hectares are:

$$
H a F_{j}=\% h_{j} * H a A=\% h_{j}(H a T o t-H a S)
$$

The numerator of the fraction (8) is always positive as it is the sum of positive amounts, the denominator must therefore satisfy the condition of existence given by:

$$
C S p S<\neq \sum_{j} \% h_{j} * C S p_{j}+S Y * \% O i l
$$

i.e. the specific consumption of sunflower plus the consumption of each single crop must be less than or equal to the energy that sunflower can produce.

The two managements (oil vs diesel) were compared; the aspects that can influence emissions into the atmosphere from the consumption of fossil fuels etc., were estimated.

During the simulation process it turned out that some farms could not use sunflower oil instead of diesel because of their high energy re- quirements for heating the farmhouse and/or greenhouse. Therefore, in order to have a homogenous comparison of all farms, farmhouse and greenhouse heating was eliminated from the simulation.

The LCA analysis was done using the software SimaPro 6 (Anonymous, 2006). This is the most widely-used software for the study and calculation of LCA worldwide. It is composed of two main sections: a database for the inventory phase (constituted of the processes and described by the inputs and outputs connected to the processes) and a database for the analysis of environmental impact. SimaPro conforms with the ISO 14000 rules, so it respects the steps of the LCA methodology: objective and field of application, inventory analysis, appraisal of the impacts and interpretation.

The agricultural production chain of sunflower oil and the other crops on the farm was analyzed from the production of the raw materials until their first off-farm transformation. We stopped at this point because much of what happens afterwards does not depend on farm management: for example the method of production (diesel or sunflower oil) of a $\mathrm{kg}$ of wheat does not influence its destiny outside the farm.

To find useful data on the construction of the processes and therefore on the models of the different farm managements considered, we mainly used the data and processes available in the SimaPro 6 database. It was necessary to modify some values, such as yields, land use, or emission values, in order to adapt the processes to the chosen farms (Tassinari, 1996; Artoni, 2006; Bedendo, 2006; Bertocco, 2006).

Each cropping technique, within the different farm managements, involves a different number of tillages, with varying intensities $(\mathrm{Ar}$ toni, 2006; Bedendo, 2006; Bertocco, 2006) and thus, with different energy use. This was taken into account by creating what we called "cultivation processes".

Once all the cultivation processes had been completed, they were assembled inside SimaPro 6 for describing the farm in the considered management type and all the crops.

Each cultivation process is composed of other sub-processes describing the flows of matter and energy within the borders of the system defined above, thus generating a cascade structure in the final model. 
In order to analyse the environmental advantages (or disadvantages) deriving from converting the farm from traditional management with diesel oil to sunflower oil a new equation was defined in order to explain the relative advantage of the conversion, combining different relative indexes:

$$
I M P_{i, j}=\frac{\operatorname{Vren}_{i, j}}{\operatorname{Vtrad}_{i, j}} \cdot 100
$$

where:

- $\mathrm{IMP}_{i, j}$ is the relative impact of the renewable management (ren) over the traditional one (trad) for the category of impacts $j$ and the farm type $i$;

- Vren $_{i, j}$ is the impact value of renewable management for the category of impacts $j$ and farm type $i$;

- $\operatorname{Vtrad}_{i, j}$ is the impact value of traditional management for the category of impacts $j$ and farm type $i$.

\section{Results}

\subsection{Pre-conversion situation}

The environmental impacts have been compared for each farm type in the two management types (Table 4). The comparisons are in relative terms to the maximum values obtained in all the simulations (16 values) and the unit of comparison is one hectare. In order to have a clearer way to interpret data, the farm management types have been compared in groups.
"SMALL" farms differ remarkably. Unspecialized farms have lower environmental impacts on all the considered categories (Figure 1), due to the few cultivated species and low inputs used. Although this farm type does not have a meaningful contribution, if compared to other farms, there is a reduction of substances with an impact on climate change after the conversion. Cattle farms and horticultural farms have more impact on the environment. These two farm types, because of intensive management, have an important reduction of compounds with an effect on climate after conversion. The horticultural farms have no particular negative effects apart from substances with an eco-toxic effect. Desegregation of data (not reported) shows that the main reason for this is due to nitrate and pesticide leaching.

Comparing the data in figure 1 (small traditionally-managed farms) with those shown in figure 2 (large farms), it can be seen that the relative impact decreases with increasing farm size. The optimised cropping techniques, plus optimisation of internal and external transport of all materials, mean that these farms "dilute" their emissions into the atmosphere. Cattle farms have the greater impact in nearly all the categories. This farm type, because of the cultivation of a large area of forage maize $(52 \%$ of the land, table 4), leaves large quantities of biomass in the soil and uses low input cropping techniques (minimum tillage, lower $\mathrm{N}$ input and so on) in order to reduce production costs.

Table 4. Distribution (\%) of farm land in traditional (Trad) and renewable farm management (Ren).

\begin{tabular}{|c|c|c|c|c|c|c|c|c|c|c|c|c|c|c|c|c|c|}
\hline \multirow{3}{*}{\multicolumn{2}{|c|}{ Farm land distribution }} & \multicolumn{4}{|c|}{ Unspecialized farm } & \multicolumn{4}{|c|}{ Horticultural farm } & \multicolumn{4}{|c|}{ Cattle farm } & \multicolumn{4}{|c|}{ Mixed farm } \\
\hline & & \multicolumn{2}{|c|}{ small } & \multicolumn{2}{|c|}{ large } & \multicolumn{2}{|c|}{ small } & \multicolumn{2}{|c|}{ large } & \multicolumn{2}{|c|}{ small } & \multicolumn{2}{|c|}{ large } & \multicolumn{2}{|c|}{ small } & \multicolumn{2}{|c|}{ large } \\
\hline & & Trad & Ren & Trad & Ren & Trad & Ren & Trad & Ren & Trad & Ren & Trad & Ren & Trad & Ren & Trad & Ren \\
\hline Wheat & $\%$ & 15 & 11 & 15 & 11 & 0 & 0 & 20 & 13 & 25 & 10 & 20 & 8 & 20 & 14 & 10 & 8 \\
\hline Grain maize & $\%$ & 85 & 63 & 40 & 30 & 0 & 0 & 10 & 8 & 0 & 0 & 0 & 0 & 40 & 28 & 40 & 30 \\
\hline Forage maize & $\%$ & 0 & 0 & 0 & 0 & 0 & 0 & 0 & 0 & 53 & 22 & 52 & 22 & 0 & 0 & 0 & 0 \\
\hline Soybean & $\%$ & 0 & 0 & 25 & 19 & 0 & 0 & 5 & 4 & 9 & 4 & 15 & 6 & 0 & 0 & 13 & 10 \\
\hline Horticultural crops & $\%$ & 0 & 0 & 0 & 0 & 100 & 69 & 65 & 47 & 0 & 0 & 0 & 0 & 25 & 18 & 9 & 7 \\
\hline Sugarbeet & $\%$ & 0 & 0 & 15 & 11 & 0 & 0 & 0 & 0 & 0 & 0 & 0 & 0 & 0 & 0 & 12 & 9 \\
\hline Sunflower & $\%$ & 0 & 26 & 0 & 25 & 0 & 31 & 0 & 28 & 0 & 59 & 0 & 58 & 0 & 30 & 0 & 24 \\
\hline Alfalfa & $\%$ & 0 & 0 & 0 & 0 & 0 & 0 & 0 & 0 & 0 & 0 & 0 & 0 & 0 & 0 & 0 & 0 \\
\hline Grapevine & $\%$ & 0 & 0 & 0 & 0 & 0 & 0 & 0 & 0 & 13 & 5 & 0 & 0 & 15 & 10 & 0 & 0 \\
\hline Poplar & $\%$ & 0 & 0 & 0 & 0 & 0 & 0 & 0 & 0 & 0 & 0 & 13 & 6 & 0 & 0 & 11 & 8 \\
\hline Set-aside & $\%$ & 0 & 0 & 5 & 4 & 0 & 0 & 0 & 0 & 0 & 0 & 0 & 0 & 0 & 0 & 5 & 4 \\
\hline Total & $\%$ & 100 & 100 & 100 & 100 & 100 & 100 & 100 & 100 & 100 & 100 & 100 & 100 & 100 & 100 & 100 & 100 \\
\hline
\end{tabular}




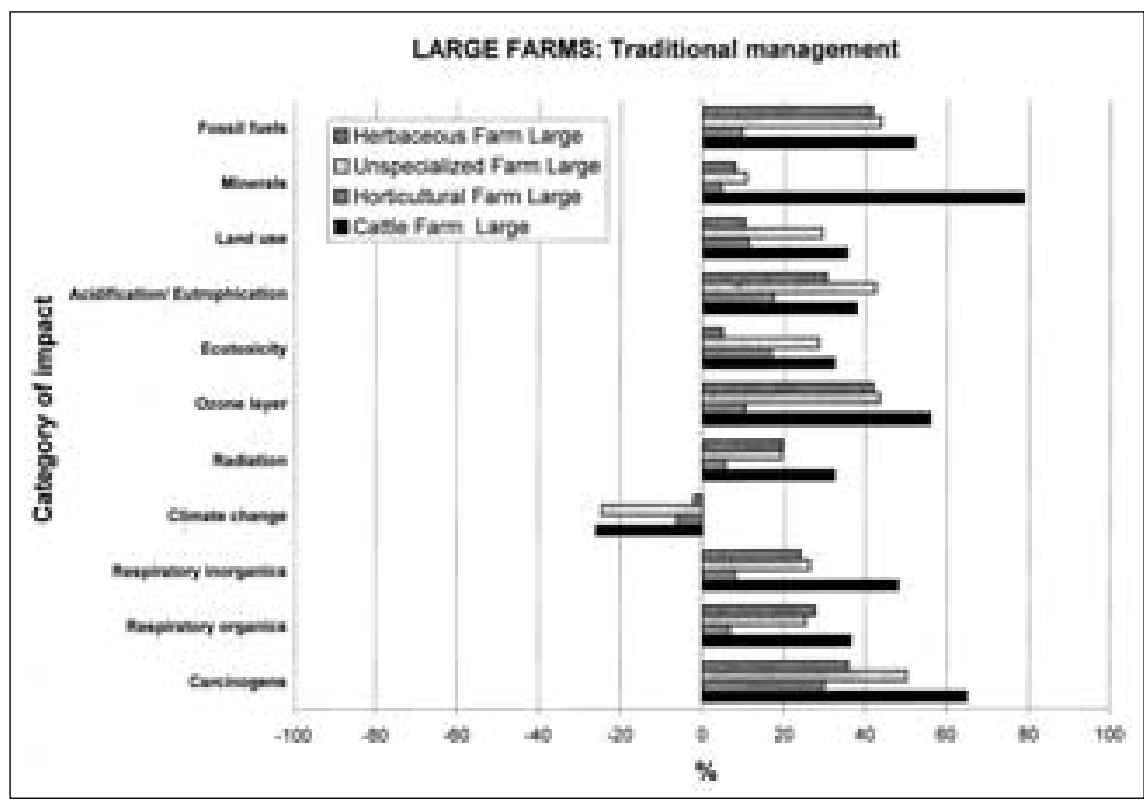

Figure 1. Simulated environmental impact for the different categories (Heijungs and Guinée, 1992) in the traditional management of small farms. The values for each category are relative to the maximum value of all farms (including large ones). The negative values express an environmental advantage of the farm.

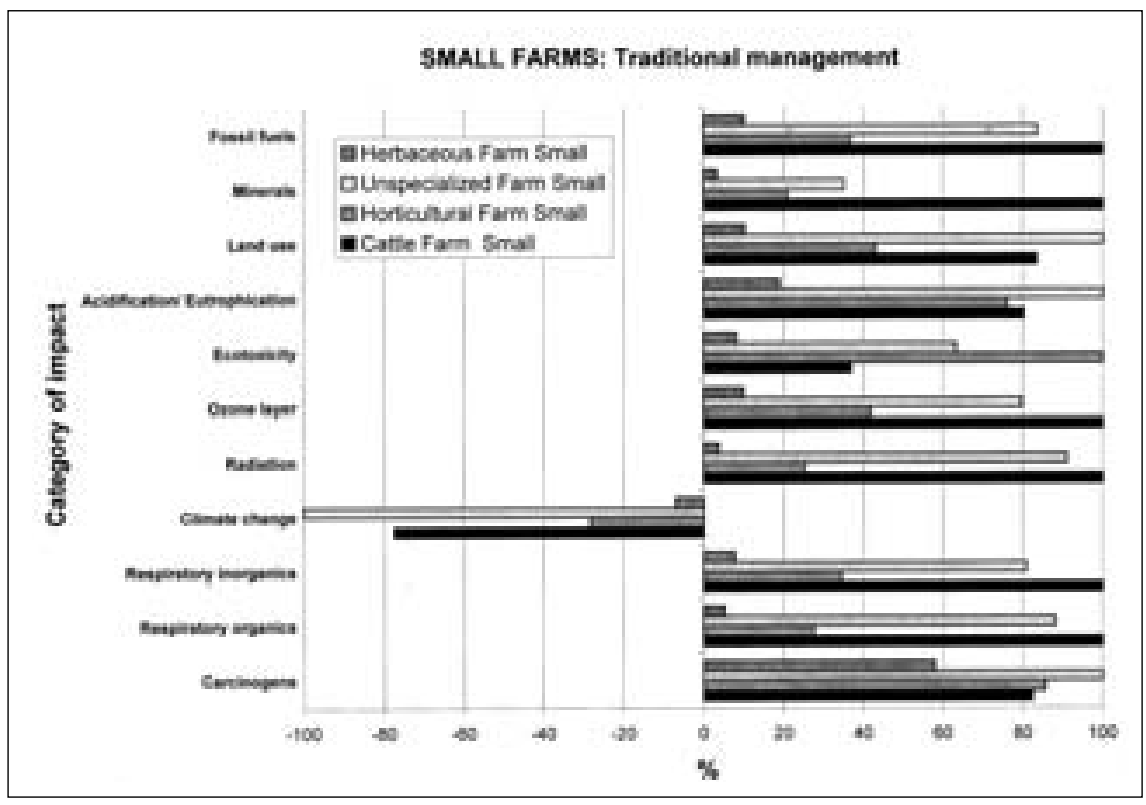

Figure 2. Simulated environmental impact for the different categories in the traditional management of large farms. The values for each category are relative to the maximum value of all farms (including large ones). The negative values express an environmental advantage of the farm.

\subsection{Post-conversion situation}

Figures 3 and 4 represent the relative advantage of the conversion to sunflower oil, with the values transformed into logarithms, because, for some farm types, the advantage of the final situation is extremely high. Therefore, the histograms in the figures that are below $100 \%$ are those for which there is an advantage in the conversion to renewable management; for values over this threshold this is not the case.
There were positive variations as a result of the substitution of diesel oil by sunflower oil (Figure 3) but not for all categories of impact. The negative variations (not reported in the text) derived mainly from the use (and therefore the building) of specialised machinery for oil extraction and filtration, the need to build suitable warehouses to house the machinery and for the tractor conversions to the use of sunflower oil.

The main environmental disadvantages were 
Figure 3. Small farms - Relative advantage of the conversion from traditional to renewable management for the categories of impact considered.

Figure 4. Large farms - Relative advantage of the conversion from traditional to renewable management for the categories of impact considered.
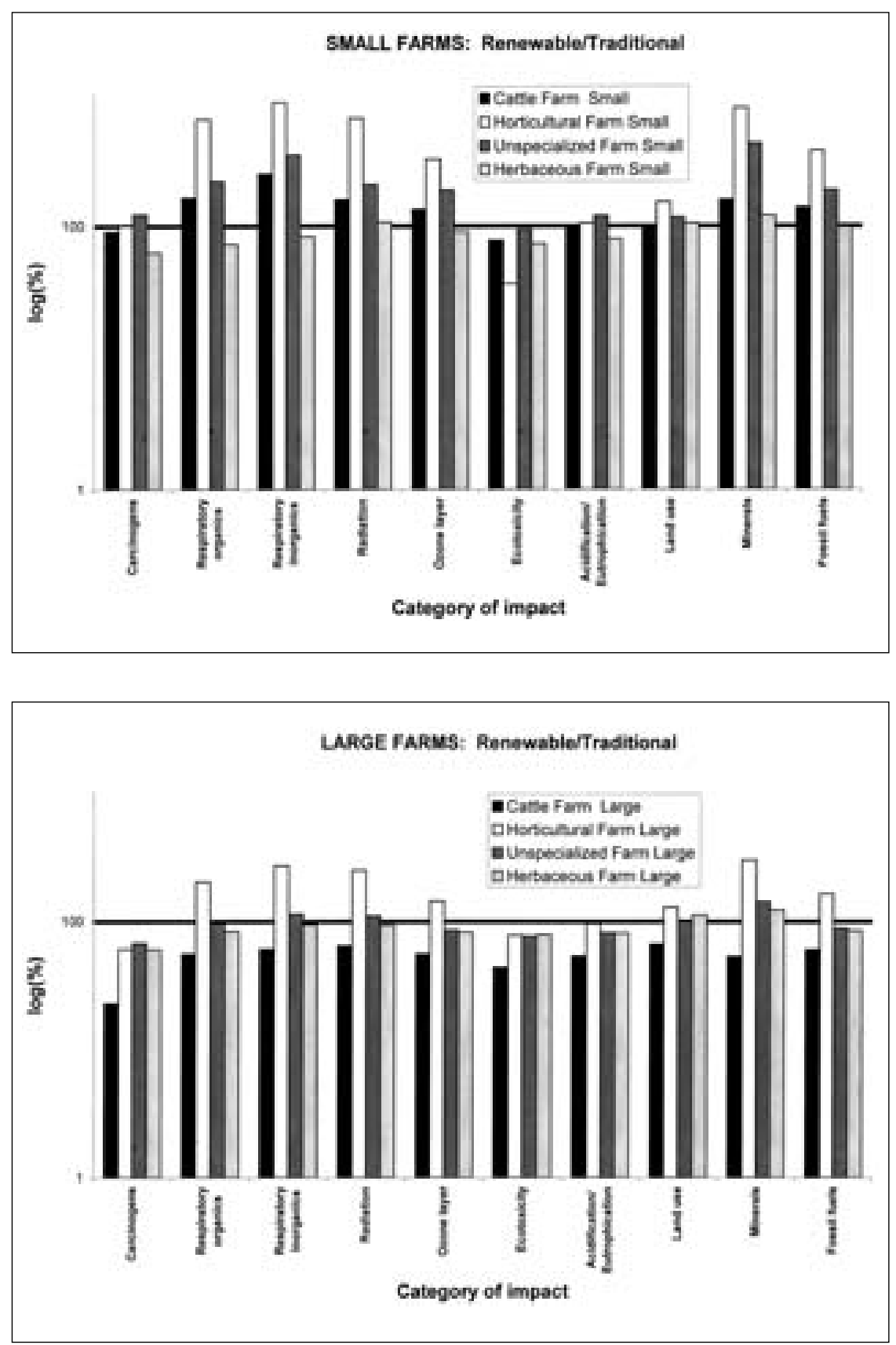

found in horticultural farm small and mixed farm small (Figure 3). In both cases the notable reduction in land growing horticultural crops lowered crop inputs, but specific warehouses had to be built to meet the high energy needs of these farms.

For the unspecialized farm small the variations in the different categories of impact are nearly always positive because there is no sub- stantial modification to the distribution of crops other than sunflower; this crop requires low inputs and replaces other crops (generally with higher input needs) on part of the land.

Similar considerations apply to large farms (Figure 4). In this case the introduction of sunflower leads to a less relevant crop redistribution on the farms (Table 4) and therefore the negative effects of the new management is "diluted" 


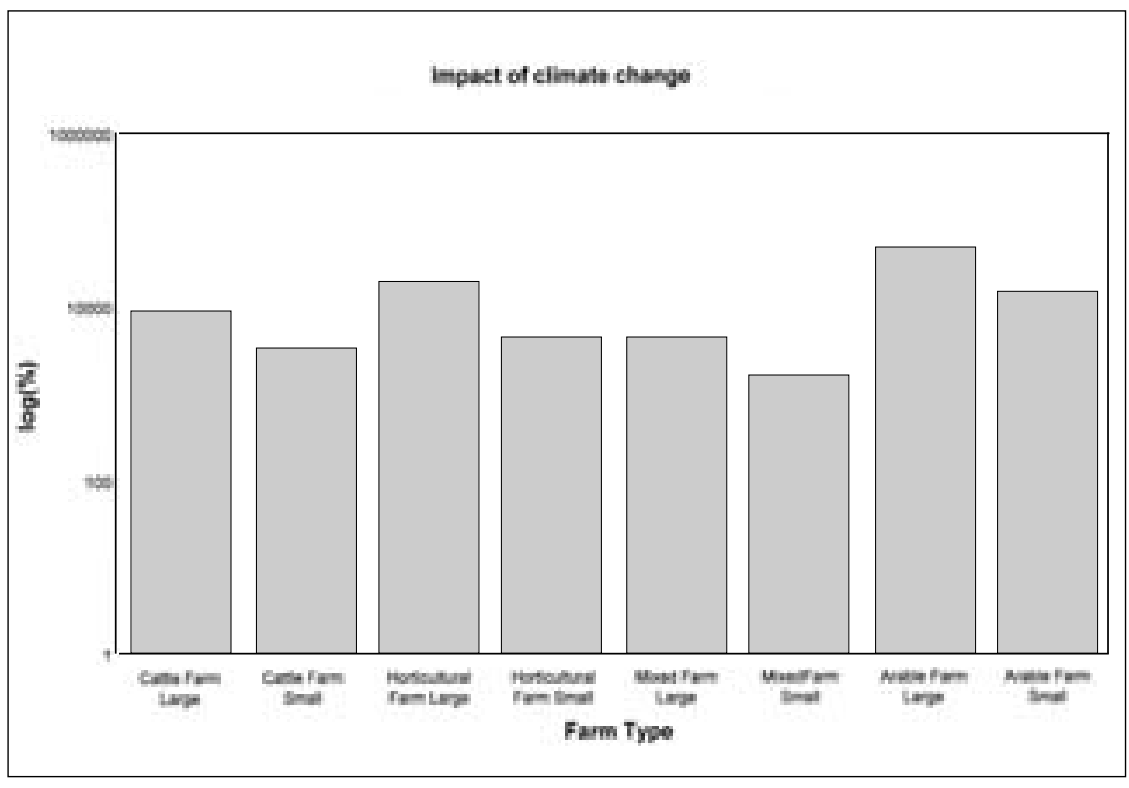

Figure 5. Relative advantage of the conversion from traditional to renewable management for the category "Substances with an effect on climate change" for all farm types. over larger areas. The main disadvantages are apparent in horticultural farms, due to their higher energy needs. Particular attention should be paid to cattle farms which only present advantages from the conversion; in fact, the use of sunflower involves a contemporary reduction in the number of animals because of the reduced forage maize growing area. This leads to a reduction in the environmental impact for the entire category.

\subsection{Combination of the different impact categories}

In order to have easily understood diagrams, we isolated the category of impact linked to compounds with an effect on the climate (Figure 5). The most obvious effect that comes out from all the simulated farm types, as expected, is a remarkable decrease in the emissions of these substances (Figure 5). In the least favourable situation (mixed farm small) there is a reduction in emissions of almost one order of magnitude, while in the best conditions (horticultural farm large and unspecialized farm, small and large) the variation is greater than two orders of magnitude. In other words, in these latter three farm types the use of sunflower oil reduces greenhouse gas emissions to less than $1 \%$.

\section{Conclusions}

For some farm types the substitution of diesel oil by sunflower oil is an interesting strategy from nearly all viewpoints (i.e., categories of impact), while for most farms this advantage is only apparent in some categories. It would be worth doing an economic balance, ante and post substitution of diesel oil, and relating it to the environmental balance; this would supply information for evaluating the costs of reduction of one category of impact. In this paper we did not consider economics, but the variations in cropping systems using sunflower oil cannot be advantageous for some farm types: for example the horticultural farm small has a large profit per unit surface area so it is not economical to reduce the cultivated land.

Obviously in order to achieve these results in Italy, some kind of financial incentives would have to be adopted but the economic balance is also positive without any state contribution. With a barrel of oil costing more than 70 euros the competition between biofuels and oil is open, or perhaps it would be better to say, is over.

Finally, it should also be mentioned that the use vegetable oil as fuel is illegal in Italy, so these conclusions are purely theoretical.

\section{Acknowledgements}

Project financed by:

1. Convenzione tra Veneto Agricoltura e Università di Padova - Dipartimento di agronomia ambientale e produzioni vegetali per Attività nell'ambito del pro- 
getto interregionale Probio - "filiere biocombustibili dal girasole".

2. Progetto "Azienda Agrienergetica": Camera Commercio Industria Artigianato Agricoltura di Padova, Provincia di Padova, AIEL (Associazione Italiana Energie Agroforestali), Coldiretti (Padova), Confederazione Italiana Agricoltori (Padova), Unione Agricoltori (Padova), Università di Padova - Dipartimento di Agronomia Ambientale e Produzioni Vegetali.

3. Progetto FISR "Sistemi e metodi di agricoltura biologica per il miglioramento della qualità delle produzioni vegetali e dell'ambiente - SIMBIO-VEG". We would like to thank Prof. Cozzi and Prof. Schiavon, Dr. Dalle Zotte and Dr. Berzaghi of the Department of Zootechnical Science of the University of Padova for providing the information on the formulation of diets and the maximum weight and size of animals allowed by law per hectare.

\section{References}

Al Hasan M. 2002. Oil from Pistachia palestine as a fuel. Biomass and Bioenergy, 23:381-386.

Anonymous 2004. RICA. http://www.inea.it/prova/ricarea/. Anonymous 2006. http://www.pre.nl/default.htm.

Araya K., Maekawa T., Kitayama M. 1987. Diesel engine performance with sunflower oil. Journal of Hokkaido Junior College, Senshu University Natural Sciences, 20: 137-154.

Artoni G. 2006. Personal communication.

Bedendo P. 2006. Personal communication.

Bernardo A., Howard Hildige R., O’ Connell A., Nichol R., Ryan J., Rice B., Roche E., Bertocco M. 2006. Personal communication.

Francescato V., Boschetti A. 2005. Produrre energia pulita nei campi è già possibile. L'Informatore Agrario, 42:23-34.
Heijungs R., Guinée J.B. 1992. Environmental life cycle assessment of products. Guide and Background, CML TNO B\&B, Leiden, The Netherlands.

Kaufman K.R., German T.J., Pratt G.L., Derry J. 1986. Field evaluation of sunflower oil/diesel fuel blends in diesel engines. Trans. ASAE, 29:2-9.

McDonnell K.P., Ward S.M., McNulty P.B., Howard Hildige R. 2000. Results of engine and vehicle testing of semirefined rapeseed oil. Trans. ASAE, 43:1309-1316

Pivato D., Tamiozzo B. 2003. L'impatto ambientale del prodotto vino. L'Informatore Agrario, 23:29-31.

RICA. 2004. Rete d'Informazione Contabile Agricola. http://www.inea.it/rica/index.html.

Riello L., Bona S. 2005. Utilizzazione dell'olio di girasole in azienda. Ed. Veneto Agricoltura, Padova, 80 pp.

Schlick M.L., Hanna M.A., Schinstock J.L. 1988. Soybean and sunflower oil performance in a diesel engine. Trans. ASAE, 31:1345-1349.

Scrosta V. 2005. Potenzialità delle biomasse per uso energetico nella regione Marche: aspetti generali ed analisi della filiera del girasole. Tesi di dottorato di ricerca in "Organizzazione degli Agro-Ecosistemi e Produttività Vegetale", Università Politecnica delle Marche, 106 pp.

Tassinari G. 1996. Manuale dell'Agronomo. REDA, Roma.

UNI EN ISO 14040. 1998. Gestione Ambientale. Valutazione del ciclo di vita: principi e quadro di riferimento.

UNI EN ISO 14041. 1999. Gestione Ambientale. Valutazione del ciclo di vita: definizione dell'obiettivo e del campo dei applicazione ed analisi dell'inventario.

UNI EN ISO 14043. 2001. Gestione Ambientale. Valutazione del ciclo di vita: interpretazione del ciclo di vita. 